\title{
USO DE PODCAST COMO FERRAMENTA PEDAGÓGICA PARA AULAS REMOTAS DURANTE O PERÍODO DE PANDEMIA DO COVID-19
}

Raphael Amaral da Câmara - raphael@dee.ufc.br

Universidade Federal do Ceará, Centro de Tecnologia, Departamento de Engenharia Elétrica Campus do Pici, av. Humberto Monte, S/N

60440-900 - Fortaleza - CE

Resumo: Este trabalho apresenta a experiência de usar o Podcast como ferramenta pedagógica para as aulas remotas durante o período de pandemia do COVID-19. A ocorrência da pandemia trouxe implicações, muitas delas inéditas, em todas as áreas da sociedade: saúde, política, econômica, social etc. Na área da educação não foi diferente e, de maneira abrupta, teve-se que romper a metodologia tradicional de transmissão do conhecimento de forma presencial para a forma remota. Neste contexto, dentre inúmeras opções de ferramentas para o ensino remoto, como vídeo aulas, aulas ao vivo etc., o Podcast aparece como uma opção viável, principalmente quando se aplica uma metodologia de ensino remoto assíncrona e, principalmente, que possua um baixo volume de consumo de dados, facilitando a inclusão de estudantes que tenham dificuldades no acesso a uma internet banda larga ilimitada, contando apenas com acesso a redes móveis com capacidade limitada de dados disponíveis. A experiência do uso de Podcast está sendo aplicada em disciplinas do curso de Engenharia Elétrica da Universidade Federal do Ceará e é apresentado um resultado parcial da percepção dos alunos com relação ao uso da ferramenta.

Palavras-chave: Ensino remoto. Pandemia. Podcast.

\section{INTRODUÇÃO}

O novo coronavírus (SARS-CoV-2), que se espalhou da China para o mundo no final de dezembro de 2019, trouxe consequências globais, muitas delas inéditas para esta geração e para a humanidade, no que diz respeito à doença da COVID-19, uma doença muito transmissível e poderosa que, infelizmente, tem tirado a vida de centenas de milhares de pessoas ao redor do planeta (HAN e YANG, 2020). A doença rapidamente mandou bilhões de pessoas para o isolamento social, se tornando uma pandemia (OMS, 2020) e paralisando inúmeras atividades presenciais, entre elas a educação superior. Instituições de Ensino Superior (IES) do mundo inteiro tiveram que postergar ou cancelar atividades como aulas, congressos, estágios, pesquisas, práticas esportivas etc. (SAHU, 2020).

Em resposta ao COVID-19, muitos países adotaram várias restrições de contato social, como restrições às viagens, distanciamento social, auto isolamento ou quarentenas, incentivando o trabalho em casa e a realização de atividades remotas (BEDFORD et al, 2020). Para a área da educação, a literatura apresenta que o fechamento das instituições de ensino reduz a transmissão do vírus na comunidade, sendo importante na quebra desta cadeia de disseminação de doenças (KAWANO e KAKEHASHI, 2015; DE LUCA et al, 2018; WHEELER, ERHART e JEHN, 2010). Por essa razão, as IESs tiveram que rapidamente fazer uma transição do ensino presencial para o ensino remoto com a utilização de várias ferramentas de ensino remoto à disposição, como vídeo aulas, chats, aulas ao vivo, entre outras (GEWIN, 
2020; LAU, YANG e DASGUPTA, 2020). Neste trabalho, o autor apresenta a experiência que tem sido a utilização de podcasts como ferramenta pedagógica para as aulas remotas durante este período da pandemia do COVID-19 em disciplinas do curso de Engenharia Elétrica da Universidade Federal do Ceará (UFC), apresentando um resultado parcial da percepção dos alunos em relação ao uso da ferramenta proposta.

\section{CONTEXTUALIZAÇÃO NO USO DO PODCAST}

O universo do podcast, onde, em uma das versões da origem de seu nome, ela vem da junção das palavras Ipod e broadcast (transmissão, do inglês) é considerado como sendo um nicho da comunidade de entusiastas em tecnologia e nerds e cresceu rapidamente em popularidade no início dos anos 2000 nos EUA (GEOGHEGAN, e KLASS, 2005). Uma definição que pode ser dada ao podcast é que ele é "um arquivo de áudio digital disponível na internet para download em computadores ou dispositivos móveis, tipicamente disponível como série, com atualizações que podem ser recebidas pelos assinantes automaticamente" (OXFORD LIVING DICTIONARIES, 2018).

O crescimento no número e na diversidade de podcasts disponíveis atualmente cobre todo tipo de assunto, especialidade e subcultura ou comunidade imaginável e a audiência tem se transformado de uma comunidade uma vez especializada (entusiastas de tecnologia e nerds) para um grande público generalizado (MOONEY, 2019). No Brasil, estima-se o público assíduo de podcasts em 50 milhões de internautas, com um público qualificado, onde a maioria é mais escolarizado e tem renda superior à média da população (MENDES, 2019). No meio acadêmico, o uso de podcasts tem início no final da década de 2000 como um instrumento complementar alternativo ou adicional e substitutivo de aulas de revisão com uma maior eficácia (FRYDENBERG , 2008; EVANS, 2008; McGARR, 2009).

Neste contexto, a utilização de podcasts como ferramenta pedagógica em algumas disciplinas de Engenharia Elétrica da UFC foi implementada no semestre letivo de 2019.1, exatamente como um complemento ao conteúdo ministrado em sala de aula, em uma tentativa de melhorar o ensino e a aprendizagem. Entretanto, com o cenário da pandemia e a adoção das atividades remotas de ensino no semestre letivo de 2020.1, que se iniciou em 17 de fevereiro, foi paralisado em 17 de março por conta da pandemia e retomado no dia 20 de julho, o podcast, que no início do semestre era uma ferramenta complementar, foi escolhido para ser utilizado como uma das ferramentas principais de transmissão de conteúdo das disciplinas onde ele já era aplicado.

Uma das razões primordiais que motivaram esta escolha, foi o fato do baixo consumo de pacote de dados. Pensando nos discentes que só teriam a disponibilidade de dispositivos móveis (smartphones e tablets) como dispositivos para acompanhamento das atividades remotas, condicionados, ainda, à uma internet móvel com limitação no pacote de dados, o uso do podcast passa a ser mais viável como ferramenta de inclusão, onde seu consumo chega a ser de no máximo $144 \mathrm{MB}$ por hora em altíssima qualidade (320 kbps) enquanto que uma videoconferência pode chegar a consumir até 3,10 GB por hora (SANTINO, 2017). Um consumo 95,35\% menor, considerando o pior caso de consumo.

Além disso, o podcast possui uma característica de mobilidade muito grande, onde o estudante não necessariamente precisa estar fixo assistindo à transmissão de uma aula ao vivo, por exemplo. Por ser uma ferramenta assíncrona e on demand, pode-se ouvir o episódio e realizar outras tarefas, como atividades domésticas, exercícios físicos, em trânsito dentro de algum meio de transporte etc. e, com a liberdade de escolher o dia e hora desejados e quantas vezes forem necessárias. 


\section{METODOLOGIA}

Para que se tivesse a percepção dos estudantes quanto à utilização do podcast como ferramenta pedagógica, foi realizada uma pesquisa através de formulário online. Aplicando uma ferramenta de business intelligence, foram gerados insights para analisar as respostas e gerar uma métrica de aprovação. A métrica escolhida foi o NPS (Net Promoter Score) que é uma medida que tenta simplificar as informações a respeito da satisfação dos consumidores e sua lealdade (REICHHELD, 2003), muito aplicada na indústria e no comércio.

O NPS funciona da seguinte forma: a(s) questão(ões) são respondidas pelos consumidores em uma escala de zero à dez, onde nove ou dez significa "promotores”, aqueles que falam bem e/ou divulgam a empresa ou serviço prestado, sete ou oito significa os "passivos", aqueles que tanto faz e, seis à zero, significa os "detratores", aqueles que não gostaram da empresa ou serviço prestado. Assim, o NPS é calculado pela diferença entre a porcentagem de detratores menos a porcentagem de promotores, conforme a equação (1).

$$
\text { NPS }=\% \text { Promotores }-\% \text { Detratores }
$$

No cálculo do NPS, os passivos são desprezados e se o resultado do NPS for negativo, significa que há mais detratores que promotores e algo precisa ser feito para melhorar esse resultado e, se for positivo, significa que há mais promotores do que detratores representando uma avaliação positiva. Apesar de na literatura haver alguns trabalhos que questionam o uso do NPS (KRISTENSEN e ESKILDSEN, 2011; KRISTENSEN e ESKILDSEN, 2011; ESKILDSEN e KRISTENSEN, 2011; ESKILDSEN e KRISTENSEN, 2011), este método ganhou popularidade, principalmente pela sua simplicidade pedagógica, ou seja, pela facilidade de se verificar quem está satisfeito, insatisfeito ou é neutro.

No contexto da educação superior, os estudantes são os “consumidores” que demonstram se estão satisfeitos, neutros ou insatisfeitos e caberá ao docente, que é a "empresa ou fornecedora de serviços”, adotar as medidas necessárias cabíveis para sempre tentar melhorar o resultado do NPS analisado, fazendo com que esta métrica seja bem aproveitada na área da educação também.

\section{RESULTADOS E DISCUSSÕES}

As disciplinas onde o podcast foi aplicado como ferramenta pedagógica são turmas das disciplinas de Eletrotécnica e, Instrumentação, Medidas e Instalações Elétricas, ofertadas pelo Departamento de Engenharia Elétrica (DEE) para todas as engenharias do Centro de Tecnologia (CT) da UFC. Cada disciplina representa uma turma e o universo de alunos nestas duas turmas e disciplinas é de 113 estudantes, onde a pesquisa contou com 37 respostas, o que estatisticamente resulta em uma pesquisa com um índice de confiabilidade de $90 \%$ e uma margem de erro de 6\% para mais ou para menos. Os tipos de questões aplicadas à pesquisa são apresentados a seguir com os seus respectivos resultados.

\subsection{Questões sociais e comportamentais}

Primeiro fez-se uma sondagem sobre alguns aspectos sociais e comportamentais do aluno, de forma bem objetiva, como, por exemplos, o tipo de internet e dispositivo disponível e, de que maneira o discente costuma a ouvir o podcast. As perguntas com os seus respectivos resultados são apresentadas na sequência: 


\section{Qual tipo de internet você tem acesso?}

Essa questão, que foi de múltipla escolha, teve o objetivo de saber a disponibilidade de internet que o discente possui, com a preocupação de entender quantos estariam com acesso limitado a uma internet móvel com pacotes de dados ou até mesmo se havia alguém sem acesso regular à internet. O resultado desta questão é apresentado na Figura 1. Observa-se que a maioria dos estudantes pesquisados (56,76\%) afirmam que possuem uma internet banda larga de boa velocidade de conexão (> 20 MB), entretanto, somados, cerca de 18,9\% estão também condicionados à uma internet móvel com limitação no tráfego de dados, tornando importante a questão do uso do pacote de dados na situação que o discente for se utilizar desta rede móvel para acompanhamento remoto das disciplinas.

Figura 1 - Respostas ao tipo de internet disponível.

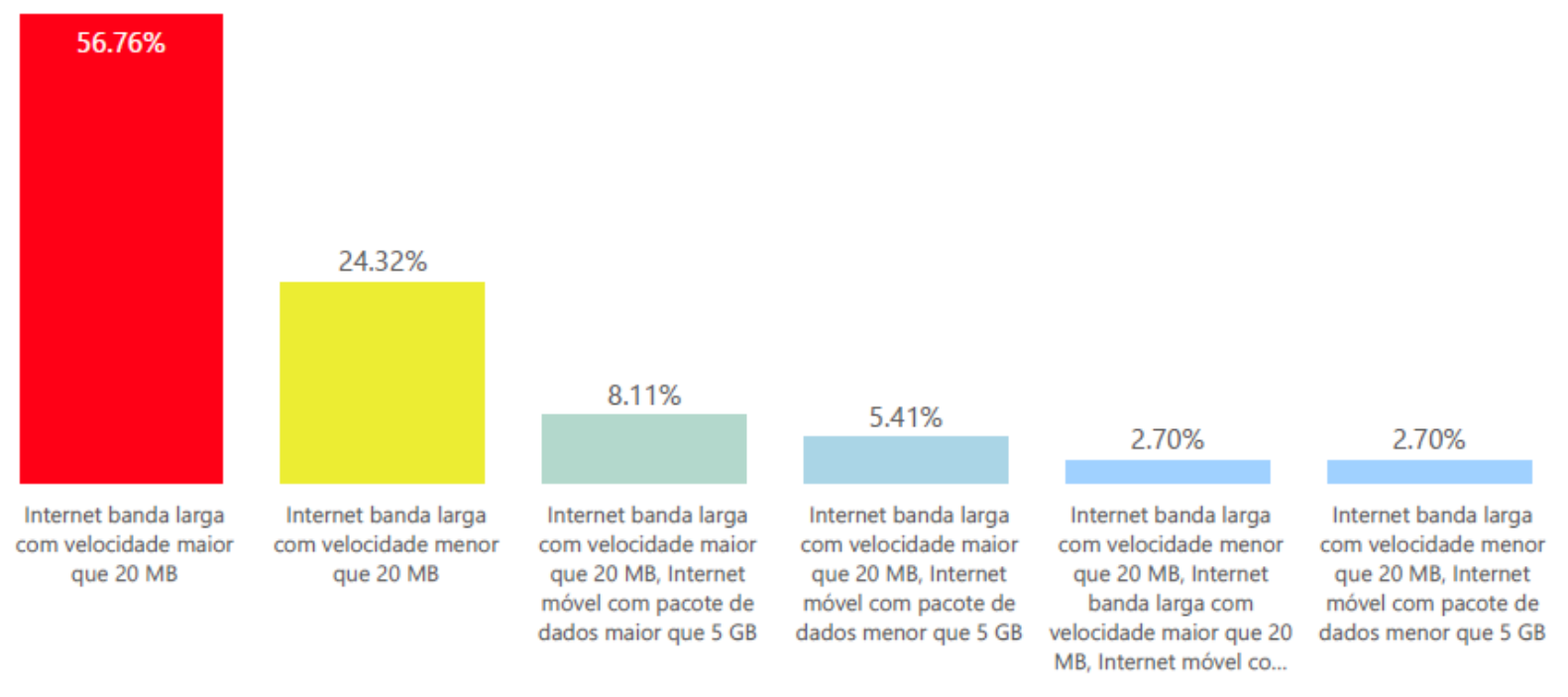

Fonte: Autoria própria

\section{Você costuma escutar o podcast de forma exclusiva ou fazendo outras tarefas?}

Nesta questão, o objetivo era saber se o estudante escuta o podcast em um local adequado e concentrado, ou seja, de forma exclusiva ou fazendo outras atividades simultâneas como afazeres domésticos, exercícios físicos, durante o deslocamento dentro de algum meio de transporte etc. O resultado desta questão é apresentado na Figura 2. Percebe-se que pouco mais da metade dos alunos pesquisados (51,35\%) afirmam escutar apenas de maneira exclusiva e que o restante, ou alternam entre às vezes escutar de forma exclusiva, às vezes não (27\%) ou escutam sempre realizando outras atividades simultâneas (21,62\%), demonstrando o potencial móvel da ferramenta que permite essa flexibilidade, fazendo a inclusão daquele aluno que, em uma situação de isolamento social, como nesta pandemia, com mais pessoas dentro da residência e, muitas vezes sem um local adequado de estudos e/ou um tempo livre exclusivo de qualidade para isso, teria mais dificuldades em acompanhar as disciplinas que possuam outras metodologias de ensino, trazendo prejuízos educacionais, sociais, e até psicológicos, se sentido excluído do processo, por exemplo. 
Figura 2 - Respostas à forma de escutar o podcast.

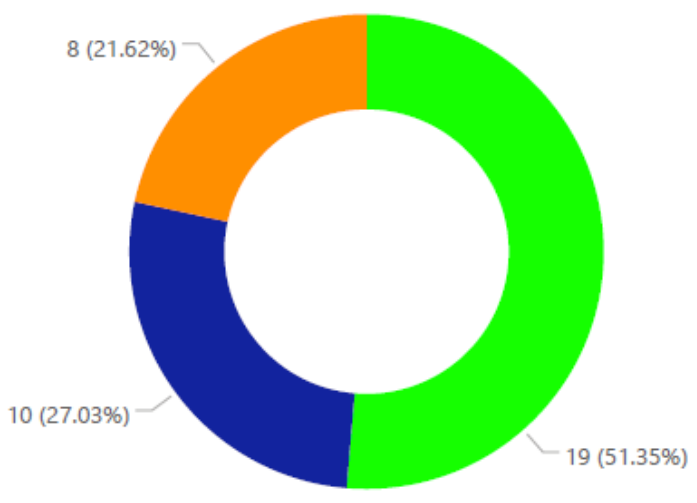

- de forma exclusiva $\bullet$ às vezes de forma exclusiva, às vezes não $\bullet$ fazendo outras tarefas

Fonte: Autoria própria

\section{Onde você costuma escutar o podcast?}

Com o objetivo de conhecer o(s) dispositivo(s) disponível(is) dos discentes, essa pergunta de múltipla escolha, cujo resultado é apresentado na Figura 3, demonstra que mais de 70\% utilizam o smartphone para acesso ao podcast, sendo que uma parcela significativa (45,95\%) o fazem de forma exclusiva. Se o resultado reflete o tipo de dispositivo disponível ao estudante para acompanhamento das aulas remotas, nota-se, mais uma vez, a importância da utilização desta ferramenta, já que visualizar vídeo aulas, por exemplo, na pequena tela de um smartphone traz algumas dificuldades para o estudante.

Figura 3 - Respostas ao dispositivo onde se costuma escutar o podcast.

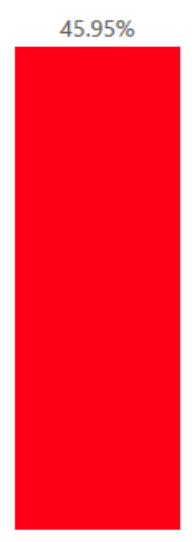

Smartphone

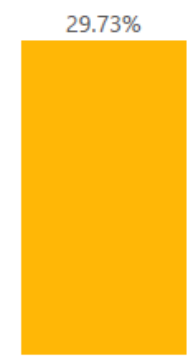

Computador

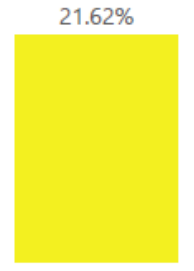

Smartphone, Computador

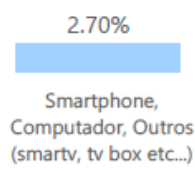

Fonte: Autoria própria

Antes da pandemia, você utilizava o podcast em seus estudos?

Por fim, dentro das questões sociais e comportamentais, foi perguntado se, antes da pandemia, quando o podcast era uma ferramenta complementar aos estudos, se os discentes escutavam ou não e, se não, quais as razões. O resultado desta questão encontra-se na Figura 4, 
onde uma parcela de $70,27 \%$ da amostragem respondeu que não escutava o podcast antes da pandemia. Dentre as razões para não terem escutado antes (era uma questão aberta), há respostas como acreditar que somente aulas presenciais eram o suficiente (resposta mais recorrente), que desconheciam esta ferramenta como forma de estudo ou que não tinha tempo para escutar. Algumas respostas, inclusive, já afirmam está sendo importante a aplicação desta ferramenta e a sua utilidade.

Figura 4 - Respostas ao dispositivo onde se costuma escutar o podcast.

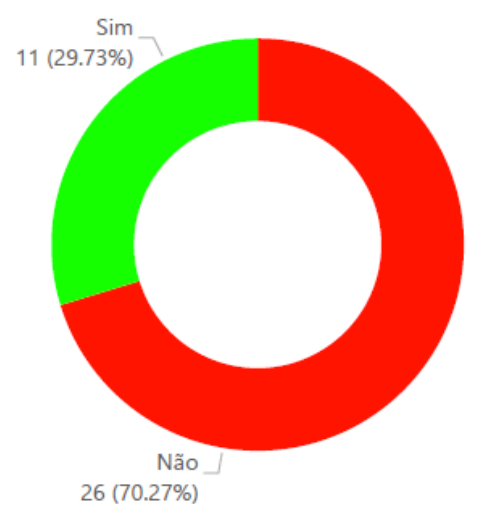

Fonte: Autoria própria

\subsection{Questões de avaliação do podcast}

Feita esta sondagem junto aos estudantes, partiu-se para questões avaliativas sobre o podcast, de modo a ter a percepção deles com relação ao uso desta ferramenta como uma das ferramentas pedagógicas principais no ensino das disciplinas. As questões com os seus respectivos NPS são apresentadas a seguir:

\section{A disponibilidade do podcast em plataformas de streaming facilitou o acesso e estimulou o seu uso?}

Antes da pandemia e no semestre letivo de 2019.2, os episódios dos podcasts eram disponibilizados no Sistema Integrado de Gestão de Atividades Acadêmicas (SIGAA), uma plataforma institucional e online adotada pela UFC e que é uma espécie de diário de turma digital, onde o professor lança notas e frequência, insere materiais de aula etc. Nesta plataforma, os discentes reclamavam que encontravam bastante dificuldades no acesso aos episódios dos podcasts, sendo que ainda era necessário realizar o download do material.

Assim, a alternativa foi publicar os episódios dos podcasts nas principais plataformas de streaming como Spotify, Google Podcasts, Apple Podcasts, entre outros. Com isso, o estudante passou a ter ainda mais flexibilidade no acesso aos conteúdos, já que essas plataformas estão disponíveis em todos os tipos de dispositivos (notebook/computador, smatphones e tablets iOS $e$ Android etc.). O NPS dessa questão é apresentado na Figura 5, com um resultado positivo de quase $60 \%$, o que demonstra que foi uma ação correta realizada e que os estudantes ficaram estimulados e satisfeitos com isso. 
Figura 5 - NPS sobre a disponibilidade do podcast em plataformas de streaming.

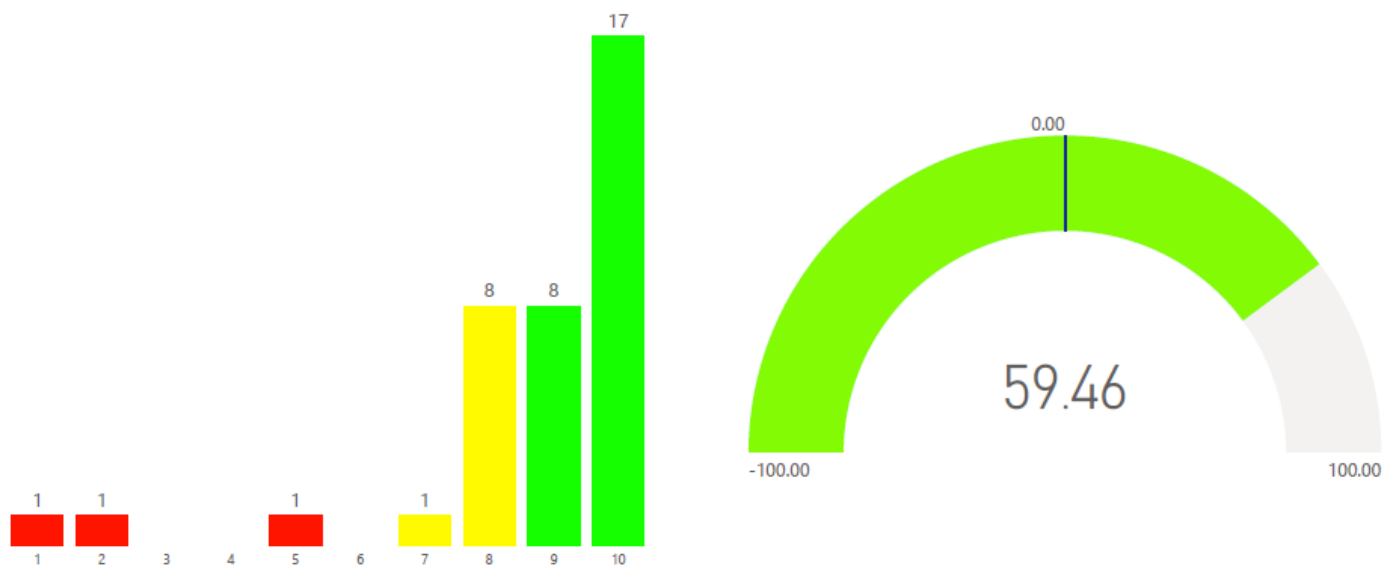

Fonte: Autoria própria

\section{Você tem gostado do uso do podcast como ferramenta pedagógica?}

Com o podcast sendo formalizado como uma das principais ferramentas pedagógicas das disciplinas, os estudantes classificaram como positivo o seu uso, com um NPS próximo de 50\% e somente 6 detratores, conforme resultado mostrado na Figura 6, corroborando com todas as premissas descritas neste trabalho.

Figura 6 - NPS sobre a aprovação do uso do podcast como ferramenta pedagógica.
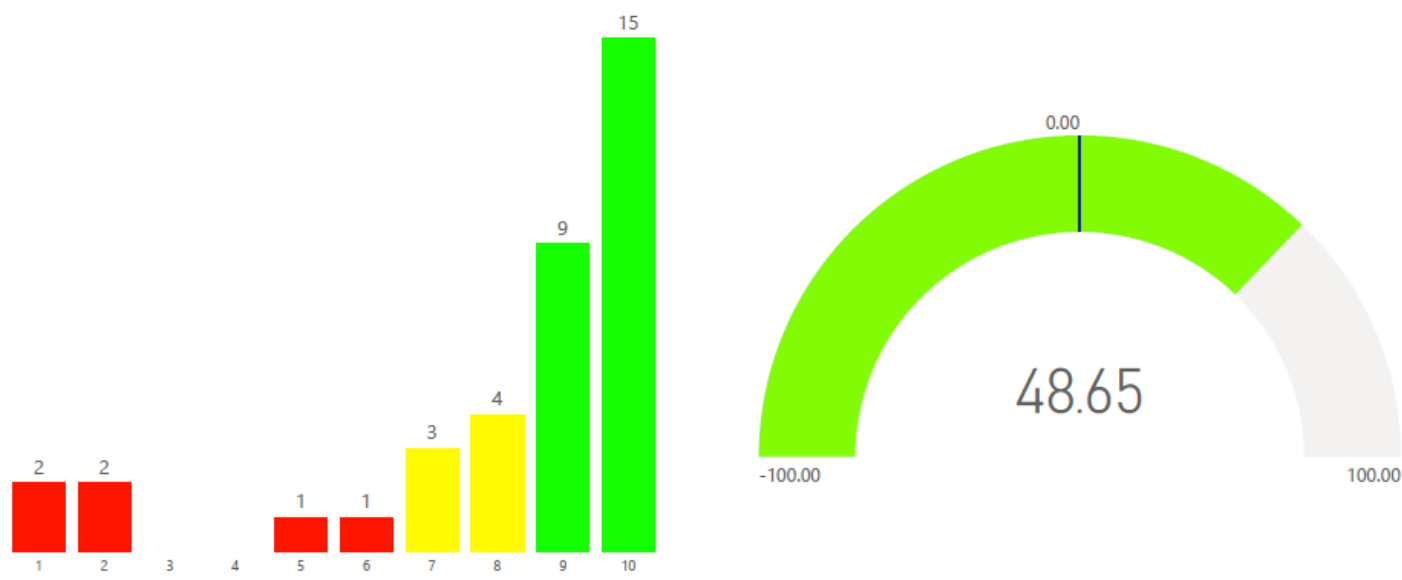

Fonte: Autoria própria

O podcast tem atingido o seu objetivo como ferramenta pedagógica na sua percepção?

Nesta questão, como pode ser observado os resultados na Figura 7 e, apesar da aprovação demonstrada na questão anterior, o NPS é mais baixo, próximo dos $22 \%$, com um número representativo de detratores. O que faz com que seja pesquisado e analisado o porquê da aprovação e, ao mesmo tempo, uma satisfação menor, no atingimento dos objetivos do podcast. 
Figura 7 - NPS sobre o atingimento do objetivo do podcast como ferramenta pedagógica.
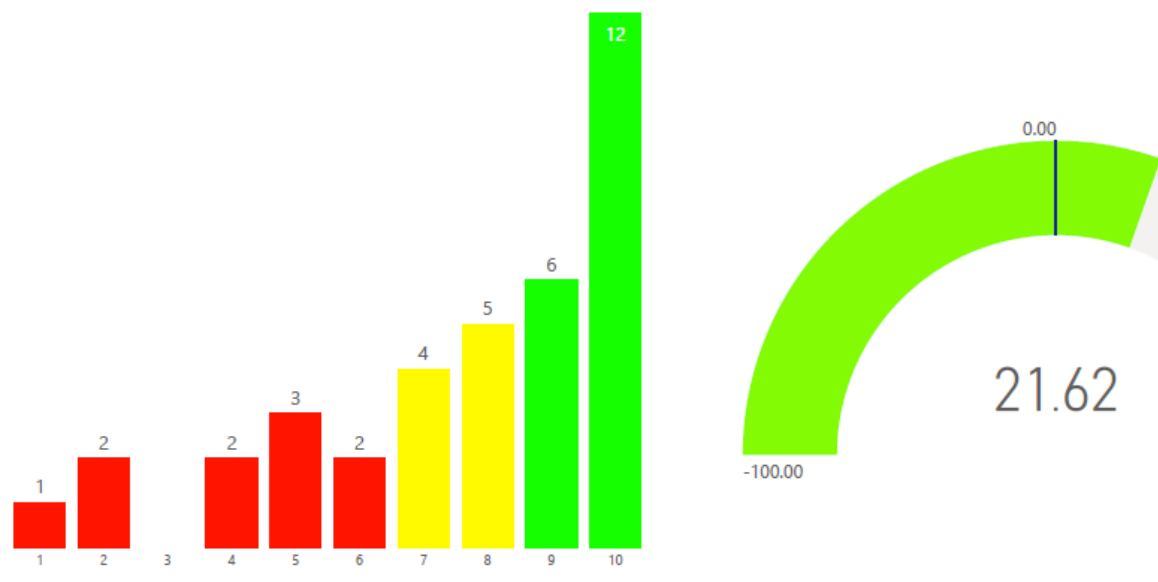

Fonte: Autoria própria

Você indicaria para um colega o uso do podcast como ferramenta de aprendizagem?

Na questão final, uma pergunta clássica de métrica de NPS: saber se há a indicação da empresa, produto ou serviços prestados para outras pessoas. Neste caso, a indicação do uso do podcast para outros colegas como ferramenta de aprendizagem. O resultado, apresentado na Figura 8, é positivo, de aproximadamente 30\%, com muitas notas dez (16 ou 43\% da amostra), demonstrando uma boa simpatia da classe estudantil com esta ferramenta.

Figura 6 - NPS sobre a aprovação do uso do podcast como ferramenta pedagógica.
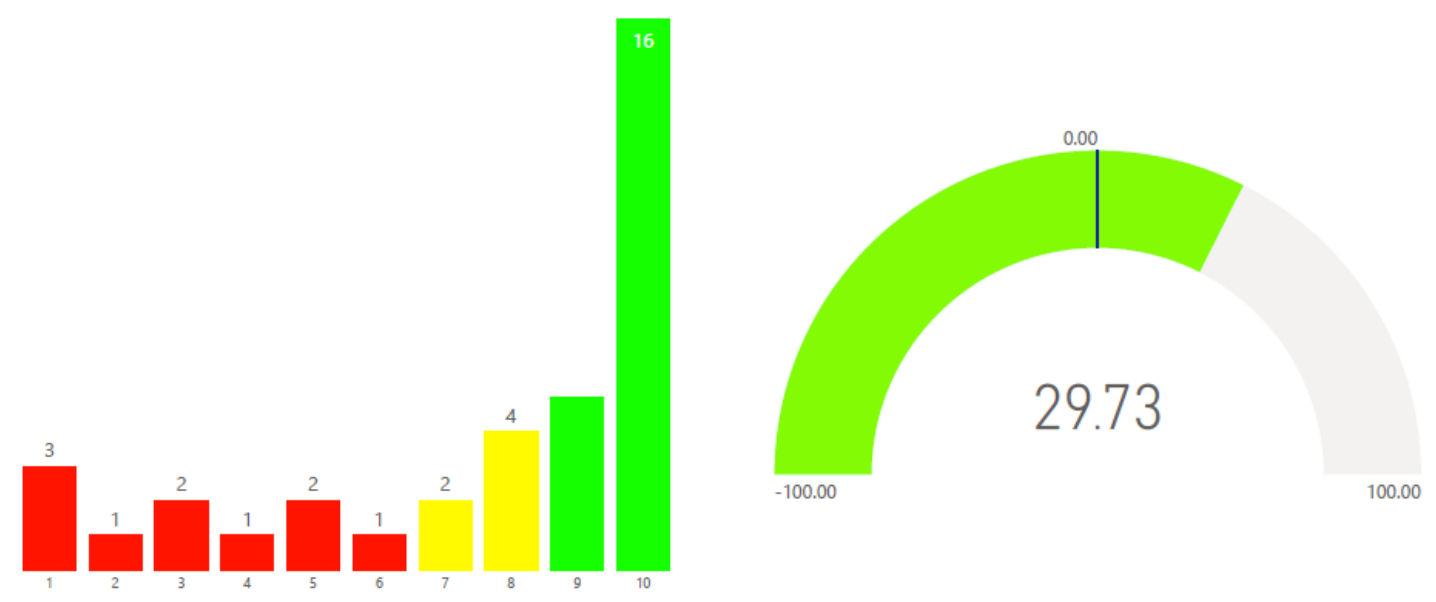

Fonte: Autoria própria

\section{CONSIDERAÇÕES FINAIS}

Neste trabalho apresentou-se a percepção dos alunos quanto ao uso da ferramenta podcast com fins pedagógicos neste contexto de pandemia da COVID-19, onde as aulas das disciplinas de Engenharia Elétrica da UFC têm sido de ministradas de maneira remota. 
Utilizando como métrica de satisfação o NPS, os resultados obtidos a partir de uma pesquisa realizada em um formulário online, foram todos positivos, comprovando uma boa aceitação por parte dos estudantes no uso desta ferramenta e indicando que o podcast é uma opção viável para ser aplicada com fins pedagógicos por ser assíncrona, móvel, flexível e de pouco consumo de dados.

Como trabalhos futuros, sugere-se uma comparação entre as disciplinas ministradas através de outras metodologias e até mesmo na forma presencial, com a metodologia utilizada neste trabalho.

\section{REFERÊNCIAS}

BEDFORD, J.; ENRIA, D.; GIESECKE, J.; HEYMANN, D. L.; IHEKWEAZU, C.; KOBINGER, G.; LANE, H. C.; MEMISH, Z.; OH, M. D.; SCHUCHAT, A.; UNGCHUSAK, K. COVID-19: towards controlling of a pandemic. The Lancet, 395(10229), p. 1015-1018, 2020.

DE LUCA, G.; VAN KERCKHOVE, K.; COLETTI, P.; POLETTO, C.; BOSSUYT, N.; HENS, N.; COLIZZA, V. The impact of regular school closure on seasonal influenza epidemics: a data-driven spatial transmission model for Belgium. BMC infectious diseases, $p$. 1-6, 2018.

ESKILDSEN, J e KRISTENSEN, K. The accuracy of the Net Promoter Score under different distributional assumptions. In: IEEE International Conference on Quality, Reliability, Risk, Maintenance, and Safety Engineering, 2011, Xi’an, China. Anais. Xi'an, 2011.

ESKILDSEN, J e KRISTENSEN, K. The gender bias of the Net Promoter Score. In: IEEE International Conference on Quality and Reliability, 2011, Bangkok, Thailand. Anais. Bangkok, 2011.

EVANS, C. The effectiveness of m-learning in the form of podcast revision lectures in higher education. Computers \& Education, 50, p. 491 - 498, 2008.

FRYDENBERG, M. Principles and Pedagogy: The Two Ps of Podcasting in the Information Technology Classroom. Information Systems Education Journal, 6(6), p. 1-11, 2008.

GEOGHEGAN, M. W.; KLASS, D. Podcast Solutions: The Complete Guide to Podcasting. New York: Editora Springer-Verlag. 2005.

GEWIN, V. Five tips for moving teaching online as COVID-19 takes hold. Nature, 580(7802), p. $295-296,2020$.

HAN, Y.; YANG, H. The transmission and diagnosis of 2019 novel coronavirus infection disease (COVID-19): A Chinese perspective. Journal of medical virology, 92(6), p. 639-644, 2020.

KAWANO, S. e KAKEHASHI, M. Substantial impact of school closure on the transmission dynamics during the pandemic flu H1N1-2009 in Oita, Japan. PloS one, 10(12):e0144839, 2015.

KRISTENSEN, K. e ESKILDSEN, J. Is the Net Promoter Score a reliable performance measure? In: IEEE International Conference on Quality and Reliability, 2011, Bangkok, Thailand. Anais. Bangkok, 2011.

KRISTENSEN, K. e ESKILDSEN, J. The validity of the Net Promoter Score as a business performance measure. In: IEEE International Conference on Quality, Reliability, Risk, Maintenance, and Safety Engineering, 2011, Xi'an, China. Anais. Xi'an, 2011.

LAU, J.; YANG, B.; DASGUPTA, R. Will the coronavirus make online education go viral? Times Higher Education. Disponível em: https://www.timeshighereducation.com/features/will-coronavirus-make-online-education-goviral. Acesso em: 29 jul. 2020. 
McGARR, O. A review of podcasting in higher education: Its influence on the traditional lecture. Australian Journal of Educational Technology, 25(3), p. 309 - 321, 2009.

MENDES, Jaqueline. Tendência mundial: empresas entram na era dos podcasts. Correio Braziliense.

Disponível

em:

https://www.correiobraziliense.com.br/app/noticia/economia/2019/08/22/internas_economia,7 78445/tendencia-mundial-empresas-entram-na-era-dos-podcasts.shtml. Acesso em: 20 jul. 2020.

MOONEY, J. A. Podcasting as faculty development medium and method: The story of a podcast series showcasing teaching excellence in higher education. Transformative Dialogues: Teaching \& Learning Journal, 1, p. 12 - 30, 2019.

OMS. Coronavirus disease (COVID-19) pandemic. Disponível em: https://www.who.int/emergencies/diseases/novel-coronavirus-2019. Acesso em: 29 jul. 2020.

OXFORD LIVING DICTIONARIES. “podcast” in The English Oxford Living Dictionary (2018). Disponível em: https://en.oxforddictionaries.com/definition/podcast. Acesso em: 29 jul. 2020.

REICHHELD, F. The one number you need to grow. Harvard Business Review, vol. 81, no. 12, p. 46-54, 2003.

SAHU, P. Closure of universities due to Coronavirus Disease 2019 (COVID-19): impact on education and mental health of students and academic staff. Cureus, 2020.

SANTINO, R. Saiba o volume de dados que você consome ao escutar música por streaming. Olhar Digital. Disponível em: https://olhardigital.com.br/noticia/saiba-o-volume-de-dadosque-voce-consome-ao-escutar-musica-por-streaming/69898. Acesso em 28 jul. 2020.

WHEELER, C. C.; ERHART, L. M.; JEHN, M. L. Effect of school closure on the incidence of influenza among school-age children in Arizona. Public health reports, 125(6), p. 851 - 859, 2010.

\title{
THE PODCAST AS A PEDAGOGICAL TOOL FOR REMOTE CLASSES DURING THE COVID-19 PANDEMIC PERIOD
}

\begin{abstract}
This paper presents the experience of using the podcast as a pedagogical tool for remote classes during the COVID-19 pandemic period. The pandemic occurrence had implications, many of them unprecedented, in all fields of our society: public health, politics, economics, social etc. In the field of education, it was no different and, abruptly, it was necessary to break the traditional methodology of transmitting knowledge in person to the remote one form. In this context, among countless options of tools for remote teaching, such as video lessons, live classes etc., the podcast appears as a feasible option, especially when applying as asynchronous remote teaching methodology and, mainly, that has a low consumption of data, facilitating the inclusion of students who have issues in accessing an unlimited broadband internet, relying only on access to mobile networks with limited capacity of available data. The experience of using podcast is being applied in subjects of the Electrical Engineering Undergraduate Program at the Federal University of Ceara - Brazil and, a partial result of the students' perception regarding the use of this tool is also presented.
\end{abstract}

Keywords: pandemic, podcast, remote teaching. 